\title{
Determination of Pore Structure in Hardened Concrete by Mercury Intrusion and Vacuum Saturated Absorption
}

\author{
Yue LI \\ The Key Laboratory of Urban Security and Disaster \\ Engineering, MOE \\ Beijing University of Technology \\ Beijing, China \\ E-mail: liyue@bjut.edu.cn
}

\author{
Hong LI \\ The Key Laboratory of Urban Security and Disaster \\ Engineering, MOE \\ Beijing University of Technology \\ Beijing, China
}

\author{
Wanguo DONG \\ The Key Laboratory of Urban Security and Disaster Engineering, MOE \\ Beijing University of Technology \\ Beijing, China
}

\begin{abstract}
Hardened concrete is a porous heterogeneous material. In this paper, pore structure of hardened concrete is determined by mercury intrusion and vacuum saturated absorption, the feasibility of these two methods is analyzed, and the linear correlation between the results detected by these two methods is created. Effects of curing ages, water cement ratio, and air-entraining agent on the porosity and pore size distribution of hardened concrete are analyzed. The results show that: 1) porosity measured by mercury intrusion can be converted into the results detected by vacuum saturated absorption with more than $90 \%$ accuracy. 2) porosity decreases as the curing age increases, and the proportion of large aperture and total pore volume also gradually reduces.
\end{abstract}

Keywords-mercury intrusion; vacuum saturated absorption; porosity; pore structure

\section{INTRODUCTION}

Pore structure is an important component of concrete microstructure, and it can significantly affect the physical and mechanical properties and durability of concrete[1-4]. Therefore, it is significant to study the pore structure of concrete. Nowadays, two test methods of mercury intrusion and vacuum saturated absorption are generally applied in this field.

Mercury intrusion is widely applied in studying pore structure of solid materials due to its practicability and reliability. Webb[5] put forward the feasibility of mercury intrusion in studying pore distribution of porous materials, and this method was used in the rapid determination of pore structure. Dim[6] studied the accuracy of mercury intrusion method improved by complementary gas adsorption and thermal analyzer. Hedenblad[7] presented the relationship between pore structure and moisture transmission characteristics in hardened cement paste by mercury intrusion. Wyrzykowski[8] investigated the pore structure in mortar with cellulose ether by mercury intrusion. Pandey[9] described the pore structure in cement. Ma[10] introduced the parameter setting and instrument usage of mercury intrusion to determinate the pore structure in hardened concrete.

The vacuum saturated absorption is mainly applied to the detection of bibulous rate of materials, and it is stipulated in some detection standards to use such method[11-14]. Williamson[15] studied the durability of aggregate by vacuum saturated absorption and regarded it as an indicator for the detection of concrete durability. Beale[16] investigated the density and water absorption of coarse aggregate by vacuum saturated absorption and considered this method is more convenient to detect the porosity of coarse aggregate than AASHTO T85 by comparing these two methods. Hall[17] improved the test method in AASHTO T85 to determinate the bibulous rate and density of coarse aggregate.

Based on the above research works, mercury intrusion has been successfully applied in the determination of pore structure. However, the preparation of samples is complex and the cost is high, and the study of determining pore structure of hardened concrete by vacuum saturated absorption is not sufficient. This paper further discusses the application of mercury intrusion and vacuum saturated absorption in determination the pore structure of hardened concrete on the basis of present researches. The linear correlation between the results detected by these two methods is created and the effects of W/C and air-entraining agent on the pore structure are considered.

\section{RAW Materials AND TeSt Method}

\section{A. Raw Materials}

The cement used in this study was Type P.I 42.5 Portland cement based on China national standard GB175-2007. The physical mechanical properties of cement are listed in Tab. I and its oxide components are shown in Table II. The concrete mixtures were prepared with crushed limestone gravel and fine aggregate which was produced based on 
China national standard GB178-77. The specific gravity of coarse aggregate was 2.7 , with a crush index of $12 \%$, and particle size distribution was from 5 to $25 \mathrm{~m}$ ). The specific gravity of fine aggregate was 2.6, fineness modulus was 2.54, and particle size distribution was from 0.16 to $5 \mathrm{~mm}$. The water reducer was polycarboxylate high-range waterreducing admixture with a water reducing rate of $30 \%$. Airentraining agent is benzene sulfonate, solid content is $3.5 \%$ and $\mathrm{pH}$ is 9 .

\section{B. Test Method}

The sample was manufactured following Table 3 of $100 \mathrm{~mm} \times 100 \mathrm{~mm} \times 100 \mathrm{~mm}$ and cured for 7 days, 28 days and 90 days following the procedure indicated in the GB/T 50081-2002

\section{1) Mercury intrusion}

AutoPore IV 9500 mercury injection apparatus (maximum mercury pressure $228 \mathrm{MPa}$, range of pore size tested $50 \AA \sim 1000 \mu \mathrm{m}$, contact angle $140^{\circ}$ and surface tension $0.485 \mathrm{~N} / \mathrm{m}$ ) produced by Micrometritics Instrument Corporation of the USA was adopted to test the samples according to Determination of Pore Size Distribution and Porosity of Solid Materials with Mercury Intrusion Method and Vacuum Saturated Absorption Method: Part 1: Mercury Intrusion Method (GB/T 21650.2008). Samples were extracted from the core of hardened concretes which were broke into small cube less than $20 \mathrm{~mm}$ diameter and emerged in anhydrous ethanol to suspend hydration and the ovendried at $60^{\circ} \mathrm{C}$ until the weight of samples was stable.

\section{2) Vacuum saturated absorption}

Porosity of hardened concrete was determined by vacuum saturated absorption in NEL-VJH (maximum vacuum is $-0.098 \mathrm{MPa}$ ). The test procedure is described in ref. [16] and [17].

\section{Mix Designs}

The mix designs of concrete are shown in Tab. I.

\section{RESULTS AND ANALYSIS}

\section{A. Porosity}

It is shown in the Fig. 1 and Fig. 2 that, porosity increase as the w/c increases, and gradually decreases as the curing age increases. Porosity measured by vacuum saturated absorption is lower than that tested with mercury intrusion. It is due to the porosity speculated by vacuum saturated absorption relies on the free water absorption of pores under an atmospheric pressure, then the volume of free water in the samples is tested and the porosity is speculated. While free water is difficult to enter some small pores under this pressure, thus, the porosity is underestimated. Porosity increases as the w/c increases due to the higher inner free water. Hydration products increase with an increasing curing age, and a part of pore is gradually filled with the cement hydration products which lead to the porosity decreases.

Function fitting of data in Fig.1-a and Fig.1-b is analyzed by MATLAB, and the equation between detected porosity of samples without air-entraining agent by mercury intrusion and vacuum saturated absorption is defined as Eq. (1). Where $\mathrm{y}_{1}(\%)$ is porosity determined by mercury intrusion, $\mathrm{x}_{1}(\%)$ is porosity determined by vacuum saturated absorption.

$$
y_{1}=-0.19306 x_{1}^{2}+5.2098 x_{1}-15.041
$$

Function fitting of data in Fig.2-a and Fig.2-b is analyzed by MATLAB, and the equation between detected porosity of samples with air-entraining agent by mercury intrusion and vacuum saturated absorption is defined as Eq. (2). Where $\mathrm{y}_{2}$ $(\%)$ is porosity determined by mercury intrusion, $\mathrm{x}_{2}(\%)$ is porosity determined by vacuum saturated absorption.

$$
y_{2}=-0.43294 x_{2}^{2}+9.9542 x_{2}-23.593
$$

Two groups of sample (group A with $0.01 \%$ airentraining agent and group B without it) with $0.35 \mathrm{w} / \mathrm{c}$ was prepared using the same raw materials and cured for $28 \mathrm{~d}$ to check the accuracy of Eq. (1) and Eq. (2). The porosity of group A and B was detected for $8.14 \%$ and $11.79 \%$ respectively by vacuum saturated absorption. The porosity calculated by Eq. (1) and Eq. (2) is $14.57 \%$ and $33.59 \%$ respectively. The actual porosity of samples tested with mercury intrusion is $15.543 \%$ and $30.642 \%$, and the error is $6.3 \%$ and $9.6 \%$ respectively, which indicates that Eq. (1) and Eq. (2)

TABLE I. ChEMICAL COMPONENTS OF CEMENT (\%)

\begin{tabular}{|c|c|c|c|c|c|c|c|c|c|}
\hline $\mathbf{S i O}_{2}$ & $\mathbf{A l}_{\mathbf{2}} \mathbf{O}_{\mathbf{3}}$ & $\mathbf{F e}_{2} \mathbf{O}_{\mathbf{3}}$ & $\mathbf{C a O}$ & $\mathbf{M g O}$ & $\mathbf{S O}_{3}$ & $\mathbf{N a}_{\mathbf{2}} \mathbf{O e q}$ & $\mathbf{f}-\mathrm{CaO}$ & Loss & $\mathbf{C l}^{-}$ \\
\hline 21.1 & 4.31 & 3.57 & 61.33 & 2.37 & 2.7 & 0.56 & 0.53 & 2.93 & 1.011 \\
\hline
\end{tabular}

TABle II. Physical Mechanical Properties of PoRtLANd CEMENT

\begin{tabular}{|c|c|c|c|c|c|}
\hline $\begin{array}{c}\text { Compressive } \\
\text { strength at 3days } \\
\text { /MPa }\end{array}$ & $\begin{array}{c}\text { Compressive } \\
\text { strength at 28days } \\
\text { /MPa }\end{array}$ & $\begin{array}{c}\text { Flexural strength } \\
\text { at 3days } \\
\text { /MPa }\end{array}$ & $\begin{array}{c}\text { Flexural strength } \\
\text { at 28days } \\
\text { /MPa }\end{array}$ & $\begin{array}{c}\text { Initial } \\
\text { setting time } \\
\text { /min }\end{array}$ & $\begin{array}{c}\text { Final setting } \\
\text { time } \\
\text { /min }\end{array}$ \\
\hline 25.1 & 46.5 & 4.5 & 8.6 & 165 & 225 \\
\hline
\end{tabular}


TABLE III. CONCRETE DESIGN

\begin{tabular}{|c|c|c|c|c|c|c|c|}
\hline Code & $\mathbf{w} / \mathbf{c}$ & $\begin{array}{l}\text { Water } \\
\mathrm{kg} / \mathrm{m}^{3}\end{array}$ & $\begin{array}{l}\text { Cement } \\
\mathrm{kg} / \mathrm{m}^{3}\end{array}$ & $\begin{array}{l}\text { Coarse aggregate } \\
\mathrm{kg} / \mathrm{m}^{3}\end{array}$ & $\begin{array}{c}\text { Fine aggregate } \\
\mathrm{kg} / \mathrm{m}^{3}\end{array}$ & $\begin{array}{c}\text { Superplastici } \\
\text {-zer }\left(\mathbf{k g} / \mathbf{m}^{3}\right)\end{array}$ & $\begin{array}{c}\text { Air-entraining } \\
\text { agent }\left(\mathbf{k g} / \mathbf{m}^{3}\right)\end{array}$ \\
\hline 1 & 0.3 & 120 & 400 & 1268 & 653 & 4 & 0 \\
\hline 2 & 0.4 & 160 & 400 & 1200 & 618 & 0 & 0 \\
\hline 3 & 0.5 & 200 & 400 & 1132 & 583 & 0 & 0 \\
\hline 4 & 0.3 & 120 & 400 & 1268 & 653 & 4 & 0.04 \\
\hline 5 & 0.4 & 160 & 400 & 1200 & 618 & 0 & 0.04 \\
\hline 6 & 0.5 & 200 & 400 & 1132 & 583 & 0 & 0.04 \\
\hline
\end{tabular}

Both have a high accuracy. However, currently, vacuum saturated absorption is only limited to the detection of porosity of concrete, and it cannot be used for detection of differential and accumulated aperture.

\section{B. Effects of Curing Ages}

Fig. 3-a is the differential aperture curve of samples with $0.3 \mathrm{w} / \mathrm{c}$ at each curing age. It is shown in the figure that, the most probable aperture, which is the aperture corresponding to the peak value, decreases significantly at 90d, suggests that the cement paste is progressively dense. It is because as the hydration degree increases, the pore is gradually filled with cement hydration products. Thus, the aperture decreases.

Fig.3-b is the accumulated aperture curves of samples with $0.3 \mathrm{w} / \mathrm{c}$ at different curing age. It can be seen that, the slope of accumulated aperture curve at $7 \mathrm{~d}$ and $28 \mathrm{~d}$ is closed. The accumulated aperture of $1000 \mathrm{~nm}$ decreases by $1.28 \%$ as the curing age increases from $7 \mathrm{~d}$ to $28 \mathrm{~d}$, and decreases by $52.86 \%$ as the curing age increases from $28 \mathrm{~d}$ to $90 \mathrm{~d}$. For the accumulated aperture curve at $90 \mathrm{~d}$, pores from $10 \mathrm{~nm}$ to $100 \mathrm{~nm}$ increases significantly, which suggests that the harmless pore (which aperture is less than 100nm) is major composition. It is due to the hydration rate enhances after cured for $28 \mathrm{~d}$, and the aperture reduces with the hydration products increases.

\section{Effects of Air-entraining Agent}

The differential aperture curves in Fig.4-1, Fig.4-3 and Fig.4-5 are compared in order to discuss the effects of airentraining agent on the pore structure. It can be clearly seen that: The most probable aperture of samples with airentraining agent at $7 \mathrm{~d}, 28 \mathrm{~d}$ and $90 \mathrm{~d}$ are $10669.83 \mathrm{~nm}$, $9310.24 \mathrm{~nm}$ and $48.17 \mathrm{~nm}$ respectively, and the samples without air-entraining agent are $60.58 \mathrm{~nm}, 57.74 \mathrm{~nm}$ and $35.85 \mathrm{~nm}$, which indicates that air-entraining agent mainly increases the probability of pore larger than $160 \mathrm{~nm}$ before cured for $28 \mathrm{~d}$. For the samples with air-entraining agent, its most probable aperture and total pore volume (which is the area between the differential aperture curve and the horizontal axis) are higher than the samples without it. Although the distinction between the most probable aperture and total pore volume of samples with and without airentraining agent decreases as the hydration degree increases, the accumulated aperture curves of samples with airentraining agent is still higher at each curing age.
Fig.4-2, Fig.4-4 and Fig.4-6 shows the effects of airentraining agent on accumulated aperture curves at different curing age. For the samples with and without air-entraining agent, cumulative percentage of pores larger than $10000 \mathrm{~nm}$ at $7 \mathrm{~d}$ is $12.19 \%$ and $38.14 \%$ respectively, and it decreases to $8.97 \%$ and $32.96 \%$ at $28 \mathrm{~d}$. It suggests that, the proportion of pores ranging from $20 \mathrm{~nm}$ to $23000 \mathrm{~nm}$ significantly increases before cured for $28 \mathrm{~d}$ with the present of air-entraining agent (there is more than $10 \%$ discrepancy between the two curves). As it is shown in Fig.4-5, two curves come across at $90 \mathrm{~d}$, cumulative percentage of pores larger than $100 \mathrm{~nm}$ in samples with air-entraining agent is lower than the samples without it, while under aperture of $100 \mathrm{~nm}$, and it is higher, which indicate that the present of air-entraining agent in concrete increases the proportion of harmless pores. It can be concluded that, the cumulative percentage of pores ranging from $20 \mathrm{~nm}$ to $23000 \mathrm{~nm}$ of samples with air-entraining agent decreases more obviously than samples without it after cured for $28 \mathrm{~d}$.

\section{Effects of $w / c$}

The differential aperture curves of samples with airentraining agent and different w/c at 28d and 90d are shown in Fig.5-a and Fig.5-b. It can be seen that, the most probable aperture of samples with $0.3,0.4$ and $0.5 \mathrm{w} / \mathrm{c}$ at $28 \mathrm{~d}$ is $1065.2 \mathrm{~nm}, 9733.54 \mathrm{~nm}$ and $10669.83 \mathrm{~nm}$ respectively, and it reduce to $35.85 \mathrm{~nm}, 41.78 \mathrm{~nm}$ and $117.23 \mathrm{~nm}$ at $90 \mathrm{~d}$, which indicates that the most probable aperture of samples for the same curing age increases as the w/c increases.

Fig.5-c and Fig.5-d shows the accumulated aperture curves of samples with air-entraining agent and different w/c at $28 \mathrm{~d}$ and $90 \mathrm{~d}$. The cumulative percentage of pores larger than $10000 \mathrm{~nm}$ of samples with $0.3,0.4$ and $0.5 \mathrm{w} / \mathrm{c}$ at $28 \mathrm{~d}$ is $15.32 \%, 21.16 \%$ and $38.14 \%$ respectively, which suggests that the aperture increases with an increasing w/c. The accumulated aperture curve of samples with $0.4 \mathrm{w} / \mathrm{c}$ is slightly higher than 0.3 , and both of the two curves slope remarkable increases when the aperture is under $100 \mathrm{~nm}$. The accumulated aperture of samples with $0.5 \mathrm{w} / \mathrm{c}$ is significantly higher than others.

\section{CONCLUSIONS}

(1) Based on vacuum saturated absorption and mercury intrusion method, the analysis of porosity of hardened concrete is achieved, the accuracy of the analysis is relatively 
high. Mercury intrusion is able to detect the differential and accumulated aperture distribution as well.

(2) A linear correlation between the measured porosity with vacuum saturated absorption and mercury intrusion is proposed. And the test results can be converted to each other through such relational expression.

(3) Porosity and aperture of hardened concrete decreases as the curing age increases, while it increases as the w/c increases. The most probable aperture increases with an increasing $\mathrm{w} / \mathrm{c}$ for the samples at the same curing age.

(4) The effects of air-entraining agent on the pore structure of concrete before cured for $28 \mathrm{~d}$ mainly shows in the increasing of most probable aperture, total pore volume and the proportion of pores ranging from $20 \mathrm{~nm}$ to $23000 \mathrm{~nm}$. The harmless pores in concrete with air-entraining agent are higher than the samples without it at 90d.

\section{ACKNOWLEDGMENT}

The authors would acknowledge the financial support of Natural Science Foundation of China (No.51278014), the Importation and Development of High-Caliber Talents Project of Beijing Municipal Institutions (CIT\&TCD20150310).

\section{REFERENCES}

[1] Diamond S, "Mercury porosimetry - an inappropriate method for measurement of pore size distributions in cement-based materials", Cem. Concr. Res., 2000, vol. 30, pp. 1517-1525.

[2] Wild S, "A discussion of the paper "Mercury porosimetry-an inappropriate method for the measurement of pore size distributions in cement-based materials" by S. Diamond". Cem. Concr. Res, 2001, vol. 31, pp. 1653-1654.

[3] Cook RA, Hover KC , "Mercury porosimetry of hardened cement paste", Cem. Concr. Res., 1999, vol. 29, pp. 1545-1553.

[4] Ji X, Ghan SYN, Feng N, "Fractal model for simulating the spacefilling process of cement hydrates and fractal dimensions of pore structure of cement-based materials", Cem. Concr. Res., 1997, 27(11), pp.1691 1699.

[5] Webb PA, "An introduction to the physical characterization of materials by mercury intrusion porosimetry with emphasis on reduction and presentation of experimental data", Norcross, GA: Micromeritics Instument Corp, 2001

[6] Dim PE, Fletcher RS, Rigby SP, "Improving the accuracy of catalyst pore size distributions from mercury porosimetry using mercury thermoporometry", Chem. Eng. Sci., 2016, vol. 140, pp. 291-298.

[7] Hedenblad G, "Use of mercury intrusion porosimetry or helium porosity to predict the moisture transport properties of hardened cement paste", Adv. Cem. Based Mater, 1997, 6 (3-4), pp. 123-129.

[8] Mateusz W, Rene K, Josef K, Robert B, Lura Pietro, "Pore structure of mortars with cellulose ether additions- Mercury intrusion porosimetry study", Cem. Concr. Compos, 2014, vol. 53, pp. 25-34.

[9] Pandey SP, Sharma RL (2000) The influence of mineral additives on strength and porosity of OPC mortar. Cem. Concr. Res. 30(1): 19-23.

[10] Ma H, " Mercury intrusion porosimetry in concrete technology: tips in measurement, pore structure parameter acquisition and application", Journal of Porous Materials, 2014, 21(2), pp. 207-215.

[11] ASTM C138. Standard test method for unit weight, Yield and Air Content of Concretes.

[12] ASTM C173, Test method for air content of freshly mixed concrete by the volumetric Method.

[13] BS 1881: Part 2, Method for air content of freshly mixed concrete by the pressure method.

[14] ASTM C457, Standard test method for microsoptical determination of parameters of air-void system in hardened concrete.

[15] Williamson GS, Weyers RE, Mokarem DW, Lane DS, Reid DD, "Vacuum saturated absorption as aggregate durability indicator", ACI Mater. J., 2007, 104 (3), pp. 307-312.

[16] Beale JM, You Z, Williams RC, Dai Q, "Determining the specific gravities of coarse aggregates utilizing vacuum saturation approach", Constr. Build. Mater., 2009, 23(3), pp.1316-1322.

[17] Hall KD, "A comparison of fine and coarse aggregate specific gravity results and variability using vacuum sealing and SS Detect methods preprint", Transportation Research Board, National Academy of Sciences, Washington DC, 2002

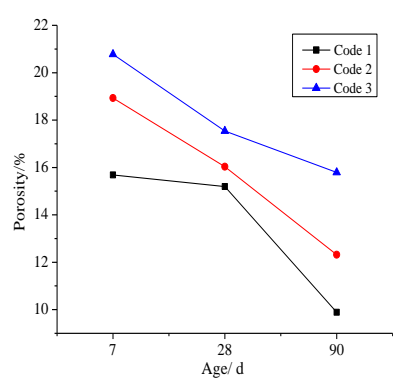

$1-(a)$

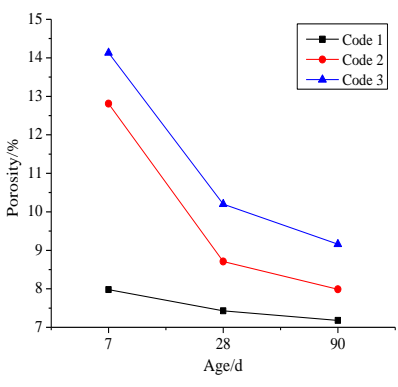

$1-(b)$

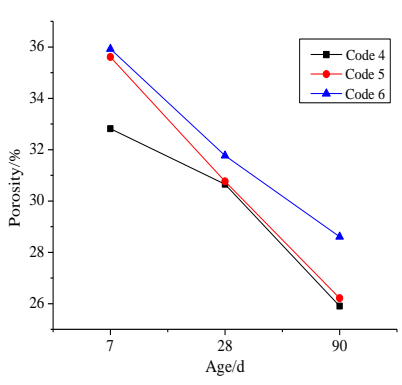

-(a)

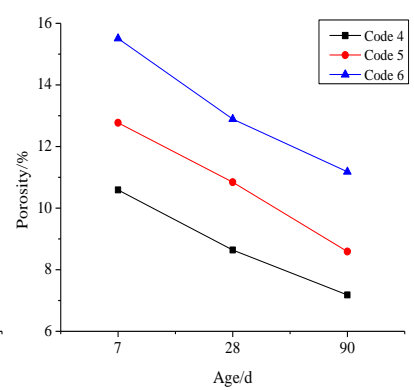

2-(b)

Figure 1. Porosity of samples without air-entraining agent determined by mercury intrusion (1-a) and by vacuum saturated absorption (1-b)

Figure 2. Porosity of samples with air-entraining agent determined by mercury intrusion (2-a) and by vacuum saturated absorption (2-b) 


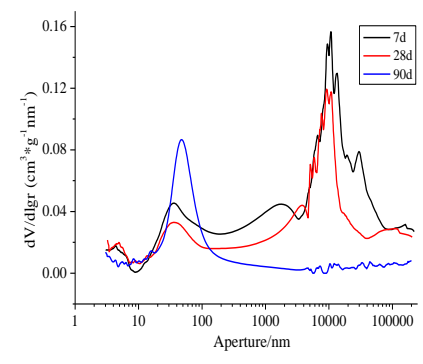

3-(a)

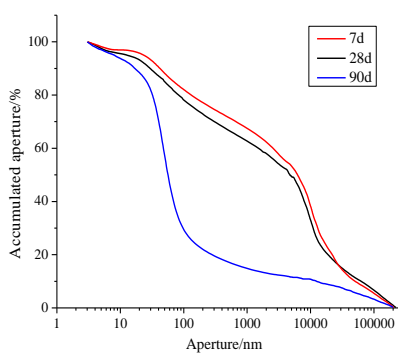

$3-(b)$

Figure 3. Differential aperture curve (3-a) and accumulated aperture curve (3-b) of samples with $0.3 \mathrm{~W} / \mathrm{C}$ determined by mercury intrusion

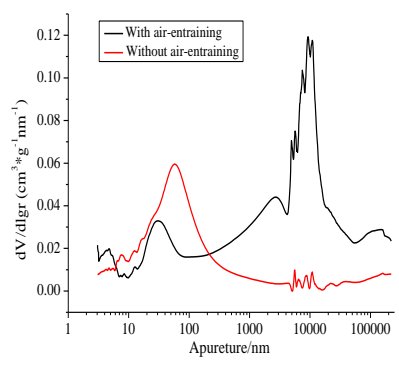

4-(3)

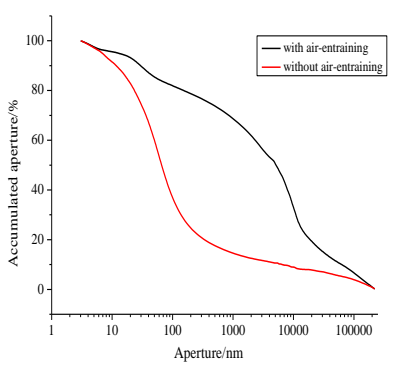

$4-(4)$

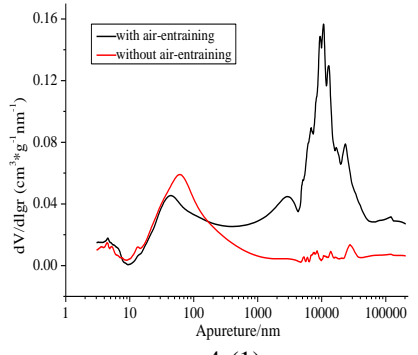

$4-(1)$

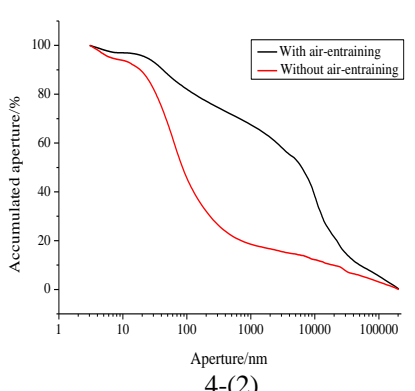

$4-(2)$

Figure 4-a Effects of air-entraining agent on the differential

Figure 4-b Effects of air-entraining agent on the differential aperture curve (4-3) and accumulated aperture curve (4-4) of samples at 28days

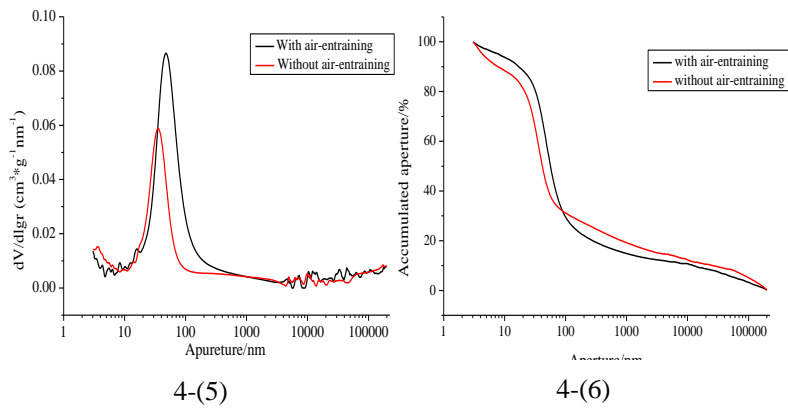

Figure 4-c Effects of air-entraining agent on the differential aperture curve (4-5) and accumulated aperture curve (4-6) of samples at 90days

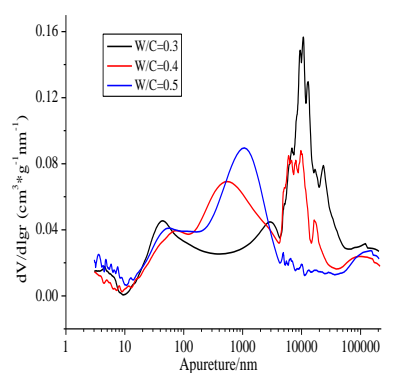

$5-(a)$

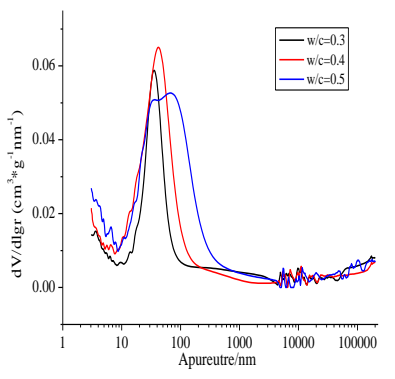

$5-(b)$

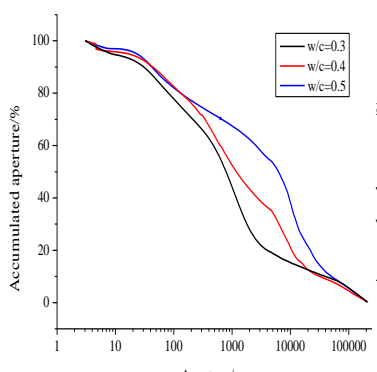

$5-(\mathrm{c})$

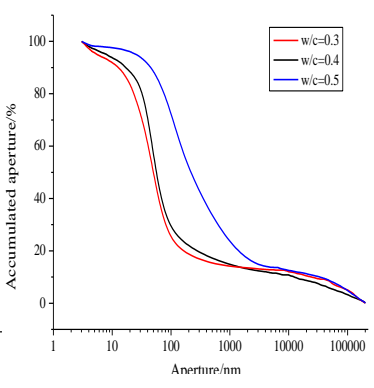

$5-(d)$

Figure 5. Differential aperture curve of samples with air-entraining agent at 28days (5-a) and 90days (5-b) and accumulated aperture curve at 28days (5-c) and 90days (5-d) 